\title{
Originals
}

\section{Increased vasopressor responsiveness to angiotensin II in Type 1 (insulin-dependent) diabetic patients without complications}

\author{
P. L. Drury', G. M. Smith ${ }^{1}$ and J. B. Ferriss ${ }^{2}$ \\ 'Departments of Endocrinology and Diabetes, St. Bartholomew's Hospital, London, UK and \\ ${ }^{2}$ Department of Medicine, Regional Hospital, Cork, Eire
}

\begin{abstract}
Summary. The blood pressure response to infused angiotensin II $\left(0.3\right.$ to $\left.3 \mathrm{ng} \cdot \mathrm{kg}^{-1} \cdot \mathrm{min}^{-1}\right)$ was investigated in six normotensive patients with Type 1 (insulin-dependent) diabetes free of complications and in six healthy subjects matched for age, sex and weight. Basal blood pressures (111/68 and $114 / 72 \mathrm{mmHg}$ ) and basal plasma angiotensin II levels $(18.0 \pm 5.2$ and $14.1 \pm 2.4 \mathrm{pmol} / 1$; mean $+\mathrm{SD})$ were similar in the diabetic and control groups as were $24 \mathrm{~h}$ urinary excretions of sodium $(157 \pm 88$ and $154 \pm 84 \mathrm{mmol} / 24 \mathrm{~h})$. Equal increments in plasma angiotensin II were produced during the infusions in the two groups. Increases in both diastolic and systolic blood pressure were significantly greater in the diabetic patients throughout the infusion. Mean diastolic
\end{abstract}

increments were: 6.7 versus $1.3 \mathrm{mmHg}(0.3 \mathrm{ng}$ dose $), 11.0$ versus $6.9 \mathrm{mmHg}$ ( $1 \mathrm{ng}$ dose) and 16.7 versus $12.3 \mathrm{mmHg}$ ( $3 \mathrm{ng}$ dose) $(p<0.001)$. Corresponding figures for systolic pressure were: 8.7 versus $1.3 \mathrm{mmHg}, 10.3$ versus $3.7 \mathrm{mmHg}$ and 15.3 versus $8.7 \mathrm{mmHg}(p<0.001)$. Vasopressor responsiveness to angiotensin II is thus increased in Type 1 diabetic patients without complications; it may, therefore, be a consequence of the diabetes rather than of the presence of microvascular disease or hypertension.

Key words: Type 1 diabetes, angiotensin II, blood pressure, vasopressor.
There have been several reports of increased pressor responses to infusion of angiotensin II (AII) in diabetes [1-4]. Christlieb reported, in eight diabetic patients with retinopathy, that the dose of AII required to produce a $20 \mathrm{mmHg}$ increment in pressure was only $40 \%$ of that required for healthy control subjects [1]. The same worker also demonstrated similar findings in alloxan diabetic rats, and showed that the abnormalities persisted after insulin treatment [2]. Weidmann et al. reported a markedly increased pressor response to infused AII in seven diabetic patients with hypertension [3], while the same group [4] have shown a lower AII pressor dose in a group of 27 subjects with either Type 1 (insulin-dependent) or Type 2 (non-insulin-dependent) diabetes, including subjects with and without retinopathy and with and without hypertension; in the latter study, basal plasma renin activity tended to be lower in the diabetic than in the normal subjects, the diabetic patients also being older.

Such hyper-responsiveness has not been explained, but has usually been attributed to the presence of diabetic microvascular disease. An alternative explanation would be that the increased exchangeable sodium reported in many studies of diabetic patients $[3,5,6]$ leads to lower plasma AII levels and thus increased responsiveness to a standard infusion. This is, however, in conflict with the only data on plasma AII levels in diabetes, where the levels were not reduced [7]. Plasma AII was not measured in the studies described above [1-4].

All these reports included patients both with Type 1 and Type 2 diabetes. As there is increasing evidence that the hypertension of Type 1 and Type 2 diabetes may differ in aetiology [8], we have performed AII infusions in a group of patients with Type 1 diabetes apparently free of complications and compared the response with that of a group of healthy control subjects matched for age, sex and body weight. In studying normotensive patients with no overt evidence of microvascular disease, our aim was to determine whether the increased pressor response was present in Type 1 diabetes per se.

\section{Subjects, materials and methods}

\section{Subjects and methods}

Six Caucasoid patients (four men, two women) with Type 1 diabetes [9] were studied. Clinical details are shown in Table 1 . None was ketotic or dehydrated at the time of study and all were considered to be 
well or moderately well controlled as out-patients. No recent adjustment had been made to their twice-daily insulin therapy. They remained on their usual carbohydrate-restricted diet but with free sodium intake; they were taking no drugs except insulin. All were, and always had been, normotensive (blood pressure $<140 / 90 \mathrm{mmHg}$ ) and none had symptoms or signs of significant retinopathy (as judged by experienced observers through dilated pupils) or peripheral or autonomic neuropathy, as judged by the complete absence of any symptoms or signs and the absence of postural hypotension. None had proteinuria as detected by Albustix (Ames, Slough, Bucks, UK) and all had creatinine clearances of greater than $70 \mathrm{ml} \cdot \mathrm{min}^{-1} \cdot 1.73 \mathrm{~m}^{-2}$.

Table 1. Characteristics of diabetic and control subjects

\begin{tabular}{lllll}
\hline & $\begin{array}{l}\text { Age } \\
\text { (years) }\end{array}$ & $\begin{array}{l}\text { Sex } \\
(\mathrm{M}: \mathrm{F})\end{array}$ & $\begin{array}{l}\text { Body } \\
\text { mass } \\
\text { index } \\
\mathrm{kg} \div \mathrm{m}^{2}\end{array}$ & $\begin{array}{l}\text { Duration of } \\
\text { diabetes } \\
\text { (years) }\end{array}$ \\
\hline Diabetic patients & & & & \\
1 & 22.5 & $\mathrm{M}$ & 22.8 & 19 \\
2 & 40.0 & $\mathrm{M}$ & 21.5 & 15 \\
3 & 23.2 & $\mathrm{M}$ & 27.4 & 13 \\
4 & 26.5 & $\mathrm{M}$ & 25.6 & 1 \\
5 & 28.8 & $\mathrm{~F}$ & 23.8 & 8 \\
6 & 23.9 & $\mathrm{~F}$ & 25.3 & 14 \\
Mean \pm SD & $30.0 \pm 5.8$ & $4 \mathrm{M}: 2 \mathrm{~F}$ & $24.4 \pm 2.1$ & $12 \pm 6$ \\
Control subjects & & & & \\
1 & 25.6 & $\mathrm{M}$ & 21.7 & - \\
2 & 37.8 & $\mathrm{M}$ & 27.9 & - \\
3 & 37.0 & $\mathrm{M}$ & 23.5 & - \\
4 & 27.8 & $\mathrm{M}$ & 21.0 & - \\
5 & 26.8 & $\mathrm{~F}$ & 19.4 & - \\
6 & 25.1 & $\mathrm{~F}$ & 21.1 & - \\
Mean \pm SD & $27.5 \pm 6.6$ & $4 \mathrm{M}: 2 \mathrm{~F}$ & $22.4 \pm 3.0$ & \\
\hline
\end{tabular}

None of the differences between the groups is significant (MannWhitney $U$ test)
Albumin excretion rates on 24-h urine collections were measured by radioimmunoassay [10]. Normal parasympathetic autonomic function was confirmed by beat-to-beat variation during deep breathing, taking 15 beats/min as the lower limit of normal at this age $[11,12]$ and sympathetic function by the blood pressure response 2 min after standing, a fall in systolic pressure exceeding $10 \mathrm{mmHg}$ being abnormal [11]. Data on renal and neurological function are given in Table 2.

Six Caucasoid control subjects (four men, two women), free of known cardiovascular, renal or endocrine disease, were studied. All were normotensive $(<140 / 90 \mathrm{mmHg})$ and had post-prandial blood glucose levels less than $6.7 \mathrm{mmol} / 1$. All were on free sodium intake and were taking no drugs.

All patients and control subjects gave written informed consent to the study, which was approved by the Hospital Ethical Committee.

The females were in the follicular phase of the menstrual cycle and had serum progesterone levels of less than $5 \mathrm{nmol} / \mathrm{l}$ at the time of study.

Details of the age, sex, body weight and duration of diabetes of the two groups are shown in Table 1; further details of the diabetic patients are provided in Table 2.

\section{Protocol}

A 24-h urine collection for sodium and potassium excretion, creatinine clearance and albumin excretion rate [10] was completed on the morning of the study. Subjects did not smoke or drink tea or coffee after $2400 \mathrm{~h}$ on the day preceding the study, but the diabetic patients took insulin $(0630$ to $0700 \mathrm{~h})$ and all subjects took an early breakfast between 0700 and $0730 \mathrm{~h}$ that morning. They lay supine from $0800 \mathrm{~h}$ when two cannulae were inserted, one into the left arm for infusion of angiotensin II and one into the right antecubital fossa for blood sampling. After $1 \mathrm{~h}$ of recumbency, a control infusion of saline $(0.154 \mathrm{~mol} / 1 ; 0.21 \mathrm{mmol} / \mathrm{h})$ was commenced at time 0 and continued for $40 \mathrm{~min}$. An infusion of angiotensin II (Hypertensin, Ciba-Geigy, Horsham, Sussex, UK) in saline $(0.154 \mathrm{~mol} / \mathrm{l})$ was then commenced, using rates of $0.3,1.0$, and $3.0 \mathrm{ng} \cdot \mathrm{kg}^{-1} \cdot \mathrm{min}^{-1}$., each dosage being continued for $40 \mathrm{~min}$. Samples for plasma angiotensin II measurement were collected as described previously [13] at times $0,40,80,120$ and $160 \mathrm{~min}$. The total amount of saline infused was $<3 \mathrm{mmol}$.

Table 2. Individual data on renal and neurological function in diabetic patients

\begin{tabular}{|c|c|c|c|c|c|}
\hline Patient number & $\begin{array}{l}\text { Creatinine clearance } \\
\left(\mathrm{ml} \cdot \min ^{-1} \cdot 1.73 \mathrm{~m}^{-2}\right)\end{array}$ & $\begin{array}{l}\text { Plasma creatinine } \\
(\mathrm{mmol} / \mathrm{l})\end{array}$ & $\begin{array}{l}\text { Albumin excretion } \\
(\mathrm{mg} / 24 \mathrm{~h})\end{array}$ & $\begin{array}{l}\text { R-R variation } \\
\text { (beats/min) }\end{array}$ & $\begin{array}{l}\text { Systolic postural } \\
\text { pressure change } \\
\text { (mmHg) }\end{array}$ \\
\hline 2 & 70 & 0.09 & 2.0 & 20 & +6 \\
\hline 3 & 80 & 0.06 & 6.6 & 16 & +16 \\
\hline 4 & 121 & 0.06 & 3.8 & 22 & -4 \\
\hline 5 & 110 & 0.06 & 7.0 & 16 & +4 \\
\hline
\end{tabular}

* Tracing technically unsatisfactory

Table 3. Biochemical data for diabetic and control subjects

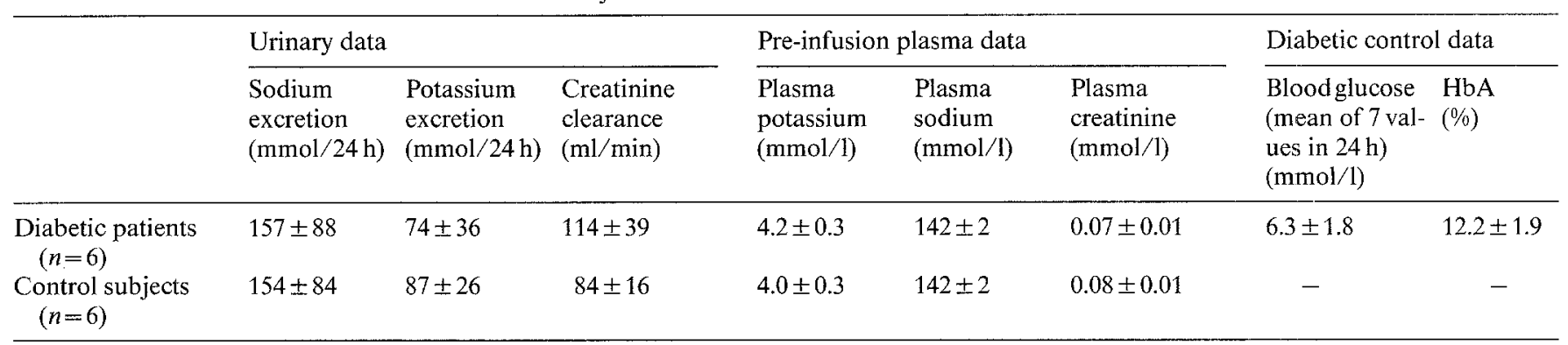

Data are presented as mean $\pm \mathrm{SD}$ 


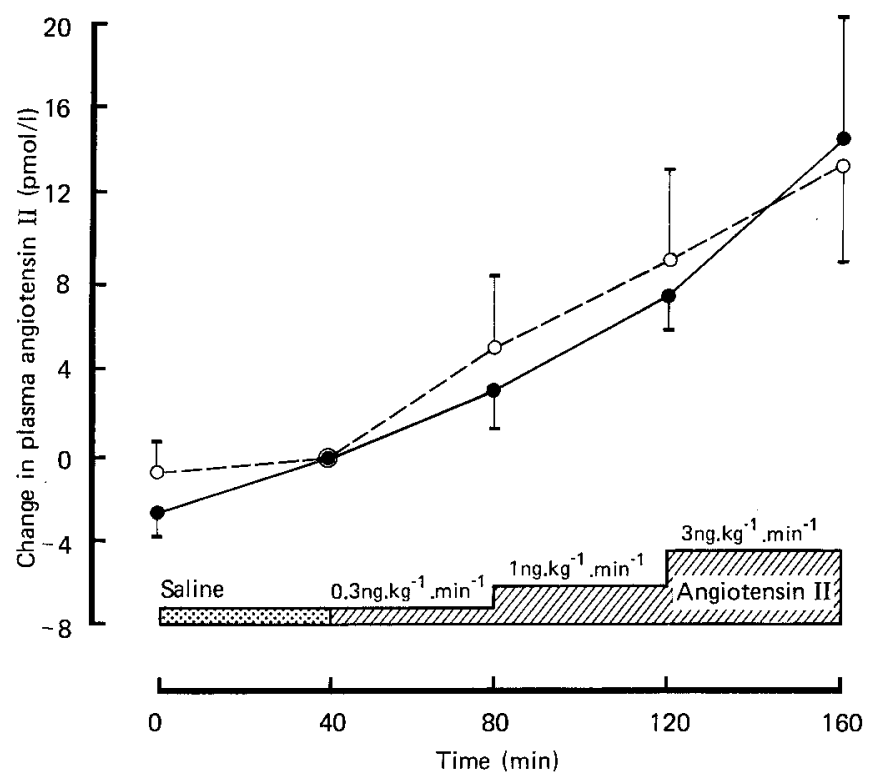

Fig. 1. Increments in plasma angiotensin II levels produced during angiotensin II infusion in six diabetic patients ( - ) and in six control subjects $\left(\mathrm{O}_{--} \mathrm{O}\right)$. Results are mean \pm SEM, taking the value at the end of saline infusion as basal. $\mathrm{Z}=$ Saline infusion; $\square=\mathrm{AII}$ infusion

\section{Blood pressure measurement}

Blood pressure was measured at $10 \mathrm{~min}$ intervals throughout the study using a mercury sphygmomanometer, recording Korotkoff phases $I$ and $V$ to the nearest $2 \mathrm{mmHg}$. Readings were made in the right arm by a single observer using the same sphygmomanometer, the calibration of which was checked before and after the study.

\section{Assessment of diabetic control}

For the $24 \mathrm{~h}$ prior to the study each diabetic subject took capillary samples (Dextrostix) on rising and at 0900,1200, 1500,1800, $2100 \mathrm{~h}$ and on retiring. These were subsequently read by a single observer using a single Glucometer machine (Ames, Slough, Bucks, UK). A sample for glycosylated haemoglobin $\left(\mathrm{HbA}_{1}\right)$ estimation was also taken on the morning of the study and measured as described previously [14]; the normal range for this assay is $6.4 \%-10.5 \%$.

\section{Other samples}

Samples were also taken before the infusion for measurement of plasma urea and electrolytes and serum creatinine. Samples for blood glucose (glucose oxidase method) and electrolytes (flame photometry) were taken at 40 -min intervals throughout the study.

\section{Assay}

Plasma angiotensin II was measured by the method of Dusterdieck et al. [13]. Inter-assay variation was $6.8 \%$ and intra-assay variation $7.0 \%$.

\section{Statistical analysis}

Age, desirable body weight and basal blood pressure were compared using the Mann-Whitney U-test. Changes in plasma electrolytes and blood glucose were compared by Student's t-test for paired samples.

In two of the diabetic patients, phase $\mathrm{V}$ measurements became briefly unrecordable during the infusion; their last preceding value
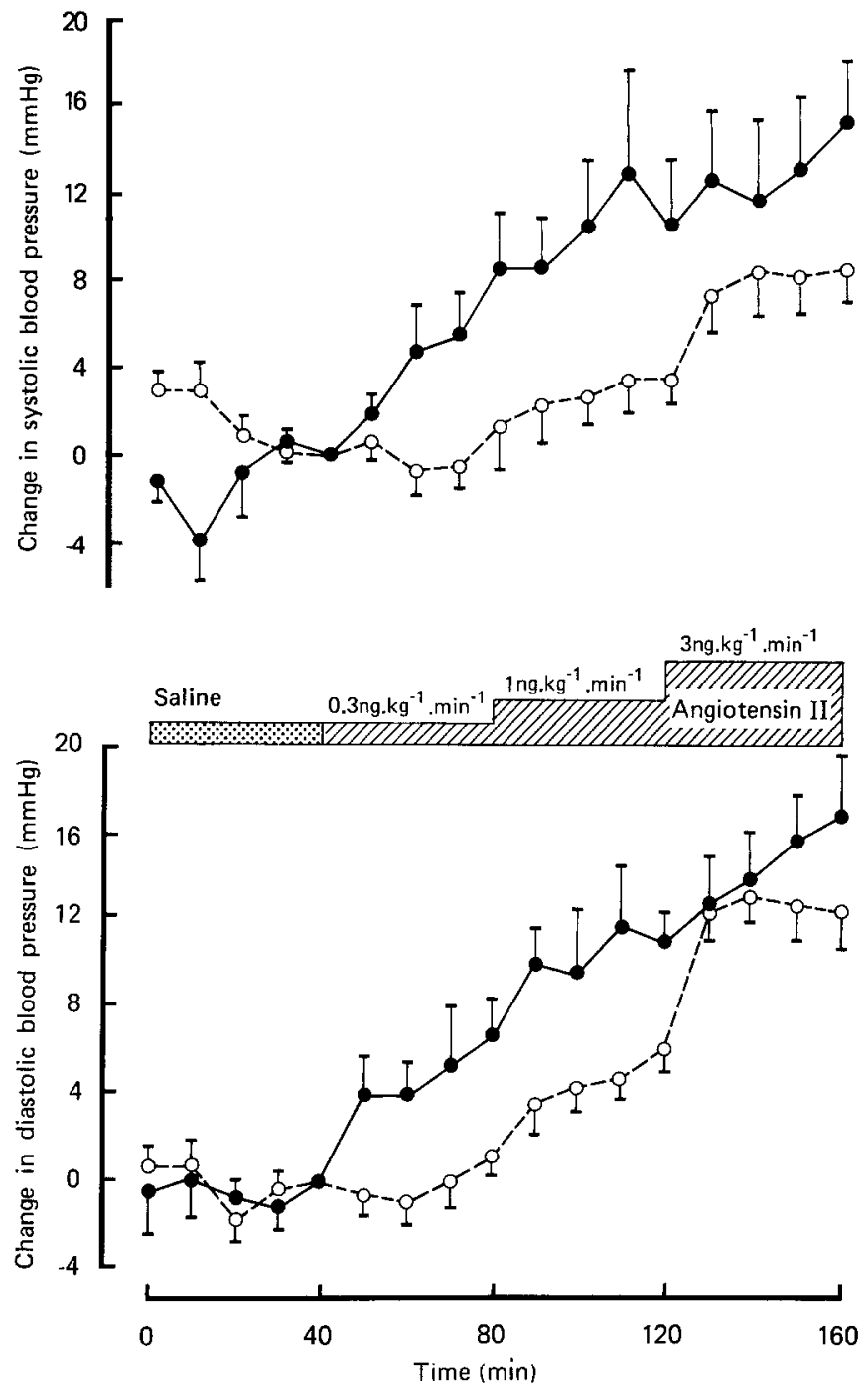

Fig. 2. Increments in systolic and diastolic blood pressure in six diabetic patients $(-1)$ and six control subjects $\left(\mathrm{O}_{--} \mathrm{O}\right)$ during AII infusion. Results are mean \pm SEM, taking the value at the end of saline infusion as basal. $\mathrm{Z}=$ Saline infusion; $Z \mathrm{Z}=\mathrm{AII}$ infusion

was used for analysis until definite phase $V$ values were again recordable.

Overall blood pressure changes during the infusion were analysed by analysis of variance, taking the pressure at the end of the saline infusion as basal.

Results are expressed as mean $\pm \mathrm{SD}$, except in figures where mean \pm SEM.

\section{Results}

All the diabetic subjects had creatinine clearance $\geqslant$ $70 \mathrm{ml} \cdot \mathrm{min}^{-1}$ per $1.73 \mathrm{~m}^{-2}$ and all had albumin excretion rates of $<30 \mu \mathrm{g} / \mathrm{min}$, five with values $<12 \mu \mathrm{g} / \mathrm{min}$ [15] (Table 2). Their beat-to-beat variations and blood pressure responses to standing were also within normal limits (Table 2 ). Urinary sodium excretion (157 versus $154 \mathrm{mmol} / 24 \mathrm{~h}$ ), basal plasma AII levels (18.0 \pm 5.2 versus $14.1 \pm 2.4 \mathrm{pmol} / 1$ ) and plasma electrolytes were also similar, though creatinine clearance values tended to be 
Table 4. Systolic and diastolic pressor responses to angiotensin II and possible related factors in individual subjects

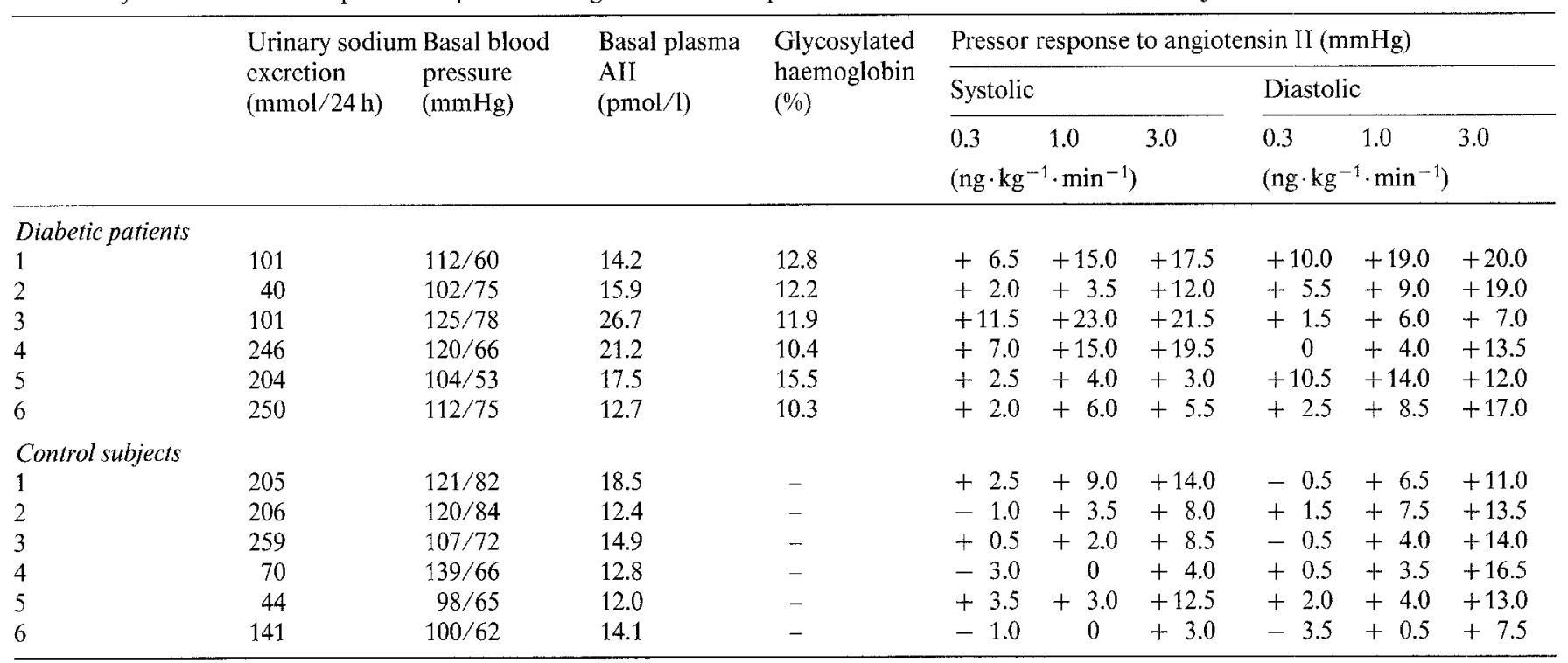

Pressure changes shown are mean of four readings during each dose of the infusion, taking the value at 40 min as basal

higher in the diabetic patients (114 versus $84 \mathrm{ml} / \mathrm{min}$; NS; Table 3). Equal increments in AII were produced during the infusion in the control subjects $(13.6 \pm$ $4.6 \mathrm{pmol} / \mathrm{l})$ and in the diabetic patients $(14.8 \pm$ 5.7 pmol/1; Fig. 1).

Both diastolic and systolic pressure responses to AII were greater in the diabetic than in the control subjects $(p<0.001$ for each, analysis of variance; Fig. 2). Mean diastolic increments at the end of each infusion period were (diabetic patients first): 6.7 versus $1.3 \mathrm{mmHg}$ ( $0.3 \mathrm{ng}$ dose), 11.0 versus $6.9 \mathrm{mmHg}$ ( $1 \mathrm{ng}$ dose) and 16.7 versus $12.3 \mathrm{mmHg}$ ( $3 \mathrm{ng}$ dose). Corresponding figures for systolic pressure were: 8.7 versus $1.3 \mathrm{mmHg}, 10.3$ versus $3.7 \mathrm{mmHg}$ and 15.3 versus $8.7 \mathrm{mmHg}$.

Individual data on pressor responses at each dose, basal blood pressures, plasma angiotensin II levels and 24-h urinary sodium excretion in the two groups are presented in Table 4.

Mean blood glucose levels in the diabetic patients fell during the study from 9.2 to $4.1 \mathrm{mmol} / 1(p<0.05$, paired t-test; Fig.3). There was a tendency for mean plasma potassium to fall in the diabetic patients (4.1 to $3.5 \mathrm{mmol} / \mathrm{l}$ ) and to rise in the normal subjects, but these were not statistically significant. Blood glucose did not change significantly in the control subjects (Fig. 3). One diabetic patient became clinically and biochemically hypoglycaemic during the study; he had shown an exaggerated pressor response before either chemical or clinical hypoglycaemia was apparent, and his blood pressure was not modified by the hypoglycaemia.

There was no significant correlation between individual pressor response and the mean blood glucose levels during the infusion or during the preceding $24 \mathrm{~h}$, nor with the $\mathrm{HbA}_{1}$ values. There was no correlation between pressor responsiveness and basal AII levels or 24-h urinary sodium excretion.
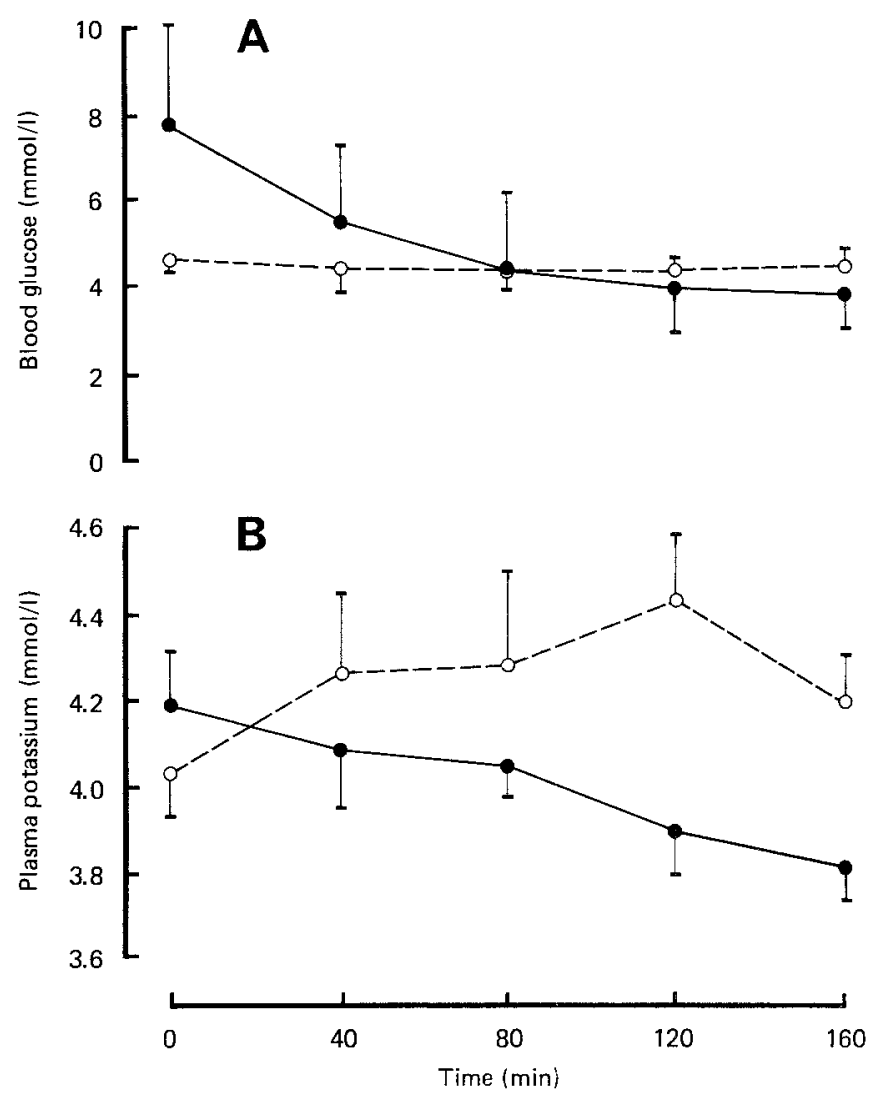

Fig. 3. Blood glucose (A) and plasma potassium (B) levels in six diabetic patients (-) and six control subjects (O-_O) during angiotensin II infusion. Results are mean \pm SEM

\section{Discussion}

We have shown an increased pressor responsiveness to angiotensin II in patients with Type 1 diabetes without evidence of any complications of their disease; this was 
particularly apparent at the lower infusion rates $\left(0.3-1.0 \mathrm{ng} \cdot \mathrm{kg}^{-1} \cdot \mathrm{min}^{-1}\right)$. It therefore appears that the increased pressor responsiveness to AII may be related to the diabetic state per se rather than to the presence of hypertension and/or retinopathy.

It is clearly not possible with non-invasive techniques to be certain of the complete absence of diabetic complications. However, retinopathy can be more easily characterised clinically than other complications and the low albumin excretion rates argue strongly against the presence of even early diabetic renal disease. The patients were all normotensive. No patient had any symptoms or signs of either peripheral or autonomic neuropathy, and beat-to-beat variations and blood pressure responses to standing were normal. Other workers [11] and our own studies (P. L. Drury and H.J. Bodansky, unpublished data) have found these criteria to be reliable in excluding sympathetic autonomic damage. We therefore believe that the group was as free of complications as practically ascertainable using non-invasive methods.

One possible criticism of the present study is that subjects were not on a fixed sodium intake. We were, however, anxious to study patients under normal circumstances and such a fixed sodium intake does not necessarily produce a similar state of total body exchangeable sodium, which several authors have shown to be consistently increased in both Type 1 and Type 2 diabetic patients $[3,5,6]$. Indeed, other studies using fixed sodium intakes for 5-7 days have failed to achieve sodium balance in diabetic subjects [16]. Given that mean 24-h urinary sodium levels on a free salt diet were similar in the diabetic and control groups, and that basal plasma AII tended to be higher in the diabetic patients, it does not seem plausible to explain our findings on the basis of higher sodium intake, and resultant lower AII levels, in the latter. In addition, there is little change in plasma renin activity, and hence AII levels, over the range of sodium intake $80-250 \mathrm{mmol} /$ day [17]. We have also shown, in a much larger group of Type 1 diabetic patients without complications (selected on identical criteria) that supine and erect plasma renin activities and concentrations are similar to those of matched non-diabetic control subjects [18]. This would not suggest an underlying suppression of plasma AII levels in Type 1 diabetes.

We therefore suggest that the increased pressor responsiveness, which has also been demonstrated with noradrenaline $[2-4,19]$, may relate to the diabetes rather than to the presence of complications. The similar increments of plasma AII produced during the infusions, and the immediate marked pressor response to the lowest dose infused, would appear to exclude decreased clearance of AII as an explanation [19]. The mechanism of the hyper-responsiveness is not clear, especially as a recent study suggested that retinal vessels in patients with microvascular disease were unresponsive to AII [20]. It is unlikely to be a direct result of insu- lin itself, or of a secondary change in plasma potassium, as a recent study showed no modification of the blood pressure response to AII in normal subjects given exogenous insulin [21]. Whatever the mechanism it might explain the increased pressor response to exercise reported by some authors [22].

Most of the previous studies showing increased pressor responsiveness in diabetic patients with retinopathy or hypertension are potentially explicable on other grounds. Thus, patients with essential hypertension have an increased blood pressure response to AII [23] while, in cross-sectional studies, diabetic patients with retinopathy tend to have higher blood pressures than those free of complications $[24,25]$; the increased response in the former may simply reflect the relative difference in blood pressure.

There was no apparent relationship between the blood pressure response and simultaneous blood glucose levels, those of the preceding $24 \mathrm{~h}$, or with glycosylated haemoglobin levels, though with only six subjects this would be difficult to show. O'Hare et al. have shown small, but significant, falls in blood pressure with improved glycaemic control of diabetes [5], and also marked falls in plasma AII with better control [5, 26]. It is clearly necessary to examine, in a within-patient study, whether altered diabetic control can modify the hyper-responsiveness.

In conclusion, we have shown that normotensive insulin-dependent diabetic subjects free of complications have a markedly increased pressor response to increments in plasma AII well within the physiological range. Such a mechanism might be important in the pathogenesis of vascular disease in the diabetic, and might contribute to exercise-induced hypertension in these subjects.

Acknowledgements. We are grateful to Dr. B. J. Boucher, London Hospital Medical College, for measurement of glycosylated haemoglobin, to Dr. G.C.Viberti for measurement of albumin excretion and to Dr. E. Shaw for statistical advice. Angiotensin II (Hypertensin) was kindly provided by Ciba-Geigy, Horsham, Sussex, UK. We thank the subjects for their willing co-operation.

\section{References}

1. Christlieb AR (1976) Vascular reactivity to angiotensin II and to norepinephrine in diabetic subjects. Diabetes $25: 268-274$

2. Christlieb AR (1974) Renin, angiotensin and norepinephrine in alloxan diabetes. Diabetes 23:962-970

3. Weidmann P, Beretta-Piccoli C, Keusch G, Gluck Z, Mujagic M, Grimm M, Meier A, Ziegler WH (1979) Sodium-volume factor, cardiovascular reactivity and hypertensive mechanism of diuretic therapy in mild hypertension associated with diabetes mellitus. Am J Med 67: 779-784

4. Beretta-Piccoli C, Weidmann P (1981) Exaggerated pressor responsiveness to norepinephrine in non-azotemic diabetes mellitus. Am J Med 71: 829-835

5. O'Hare JA, Ferriss JB, Twomey BM, Gonggrijp H, O'Sullivan DJ (1982) Changes in blood pressure, body fluids, circulating angiotensin II and aldosterone, with improved diabetic control. Clin Sci $63: 415 s-418 s$ 
6. Beretta-Piccoli C, Weidmann P (1982) Body sodium-blood volume state in non-azotemic diabetes mellitus. Mineral Electrolyte Metab 7:36-47

7. Ferris JB, Sullivan PA, Gonggrijp H, Cole M, O'Sullivan DJ (1982) Plasma angiotensin II and aldosterone in unselected diabetic patients. Clin Endocrinol 17: 262-269

8. Drury PL (1983) Diabetes and arterial hypertension. Diabetologia 24: $1-9$

9. National Diabetes Data Group (1979) Classification and diagnosis of diabetes mellitus and other categories of glucose intolerance. Diabetes 28: 1039-1057

10. Keen H, Chlouverakis C (1963) An immunoassay method for urinary albumin at low concentrations. Lancet 2: 913-916

11. Wieling W, van Brederode JFM, de Rijk LG, Borst C, Dunning AJ (1982) Reflex control of heart rate in normal subjects in relation to age: a database for cardiac vagal neuropathy. Diabetologia 22: $163-166$

12. Wieling W, Borst C, van Dongen Torman MA, van der Hofstede JW, van Brederode JFM, Endert E, Dunning AJ (1983) Relationship between impaired parasympathetic and sympathetic cardiovascular control in diabetes mellitus. Diabetologia 24: 422-427

13. Dusterdieck G, McElwee G (1971) Estimation of angiotensin II concentration in human plasma by radioimmunoassay: some applications to physiological and clinical states. Eur J Clin Invest 2: 32-38

14. Welch SG, Boucher BJ (1978) A rapid microscale method for the measurement of haemoglobin $A_{1}$. Diabetologia 14: 209-211

15. Viberti GC, Hill RD, Jarrett RJ, Argyropoulos A, Mahmud R, Keen H (1982) Microalbuminuria as a predictor of clinical nephropathy in insulin-dependent diabetes mellitus. Lancet 1: $1430-1432$

16. Fernandez-Cruz A, Noth RH, Lassman MN, Hollis JB, Mulrow PJ (1981) Low plasma renin activity in normotensive patients with diabetes mellitus: relationship to neuropathy. Hypertension 3: $87-92$

17. Brunner HR, Laragh JH, Baer L, Newton MA, Goodwin FT, Krakoff LR, Bard RH, Buhler FR (1972) Essential hypertension. Renin and aldosterone, heart attack and stroke. N Engl J Med 286: $441-449$
18. Drury PL, Bodansky HJ, Oddie CJ, Edwards CRW (1984) Factors in the control of plasma renin activity and concentration in Type 1 diabetes. Clin Endocrinol 20:607-618

19. Berretta-Piccoli C, Weidmann P (1982) Total plasma clearance of infused norepinephrine in non-azotaemic diabetes mellitus. Klin Wochenschr 60:555-560

20. Rhie FH, Christlieb AR, Sandor T, Gleason RE, Rand LI, Shah ST, Soeldner JS (1982) Retinal vascular reactivity to norepinephrine and angiotensin II in normals and diabetics. Diabetes 31: $1056-1060$

21. Vierhapper $H$, Waldhausl W, Nowotny $P(1983)$ The effect of insulin on the rise in blood pressure and plasma aldosterone after angiotensin II in normal man. Clin Sci 64: 383-386

22. Mogensen CE, Vittinghus E, Solling K (1979) Abnormal albumin excretion after two provocative renal tests in diabetes: physical exercise and lysine injection. Kidney Int 16: 385-393

23. Marks AD, Marks DB, Kim YN, Moctezuma J, Adlin EV, Channick BJ (1978) The pressor response to angiotensin II in patients with low renin essential hypertension. Circ Res 42: 864-869

24. Drury PL, Bodansky HJ, Oddie CJ, Cudworth AG, Edwards CRW (1982) Increased plasma renin activity in Type 1 diabetes with microvascular disease. Clin Endocrinol 16: 453-461

25. Dornan TL, Mann JI, Turner R (1982) Factors protective against retinopathy in insulin-dependent diabetics free of retinopathy for 30 years. Br Med J 285: 1073-1077

26. Sullivan PA, Gonggrijp H, Crowley MJ, Ferriss JB, O’Sullivan DJ (1980) Plasma angiotensin II and the control of diabetes mellitus. Clin Endocrinol 13: 387-392

Received: 17 November 1983

and in revised form: 10 May 1984

Dr. P. L. Drury

Departments of Endocrinology and Diabetes

St. Bartholomew's Hospital

West Smithfield

London EC1A 7BE,

UK 